\title{
The Belt and Road: Mutual Connectivity, Shared Prosperity
}

\section{Wu Wenhua}

Institute of Comprehensive Transportation of China Macro-economy Academy, Beijing, China

\section{Email address:}

wuwh@ict.org.cn

\section{To cite this article:}

Wu Wenhua. The Belt and Road: Mutual Connectivity, Shared Prosperity. International Journal of Transportation Engineering and Technology. Vol. 4, No. 2, 2018, pp. 31-34. doi: 10.11648/j.ijtet.20180402.12

Received: May 17, 2018; Accepted: June 25, 2018; Published: July 26, 2018

\begin{abstract}
As one of the six thematic sessions on the topic of the "the Belt and Road International Cooperation Forum", infrastructure connectivity with the theme of "Connectivity and Prosperity", has cooperated with all sides to discuss transportation, energy and telecommunication in China. In the future, the global infrastructure upgrades and interoperability, transportation, energy and telecommunication technology integration development, will have new power to stimulate economic growth. In the construction of a new generation of infrastructure network system, the late-developing countries face a rare opportunity for leapfrog development, and the experience of China's infrastructure development is of great significance.
\end{abstract}

Keywords: The Belt and Road, Connectivity, Cooperative Development, Prosperity

\section{Background}

On May 14 and 15 of 2017, Belt and Road (B\&R) Forum for International Cooperation was held in Beijing, which included Infrastructure Connectivity as one of the six thematic sessions on the topic of connectivity and shared Prosperity, where countries discussed the collaboration of infrastructure connectivity in transportation, energy and telecommunication. Infrastructure connectivity is an active move to promote the Belt and Road Initiative and plays the role of forerunner and supporter. The future infrastructure construction is going to enter the stage of international connectivity and intelligent development, which is crucial to the economic boost and social welfare. Through a collaboration of construction and sharing, we will build a bridge of worldwide common prosperity and render the Belt and Road (B\&R) one of the megastructures in the history of human development.

\section{Infrastructure Connectivity Is an Active Move to Promote Belt and Road Initiative}

Infrastructure connectivity is the priority area under Belt and Road Initiative and is the base and platforms for the connections of other four areas of B\&R [1]. Infrastructure connectivity facilitates and is facilitated by the other four "connections": bi- or multi-lateral policy communication and discussion is the prerequisite for infrastructure connectivity, currency circulation and financing and investment institutional arrangement ensures the construction of various infrastructure, and infrastructure connectivity builds the bridge of communication and understanding for common aspiration.

Ever since the initiative of B\&R, over 100 countries and international organizations has actively responded with positive support. Led by the high-level consensus and political mutual trust, China has signed MOU with more than 40 countries and international organizations on $B \& R$ collaboration, to promote the connections in infrastructural planning and construction, comprehensive service delivery, quality technology and standard, and political mechanisms in transportation, energy and telecommunications, and to strengthen the financial support, from which facilitated the construction of a number of mega-projects and became the area that gained the first harvest from B\&R Initiative.

\subsection{Collaboration in Transportation Reached Significant Accomplishments}

Railway projects, especially high-speed railway going-out, has been a shining "Made in China" namecard to the world, with Ethiopia to Djibouti railway open to traffic, and Hungary-Serbia Railway, Jakarta to Serbia high-speed railway, China-Laos railway, Tehran-Isfahan high-speed railway, 
Moscow-Kazan high-speed railway having made smooth progress. Through cooperation with $\mathrm{B} \& \mathrm{R}$ countries and promotion in clearance and logistics facilitation, China began to run China Railway Express that crosses over Eurasian Continent and stretches more than 10,000 kilometers, and constructed overland transportation corridor connecting Asia and Europe, which has become a new brand of international logistics. Jamaica north-south highway, Ethiopia AA highway, Laos Route 13(Pa Mong to Phongsaly), and Penang Second Bridge of Malaysia have completed construction; China-Pakistan Multan-Sukkur Highway, China-Russia Heihe-Blagoveshchensk road port bridge, Pakistan Sukkur-Lahore highway, second phase project of China-Pakistan Karakoram Highway upgrading, and Maldives China- Maldives Friendship Bridge are now running smoothly on construction. Road connectivity and cross-border transport service level have been uplifting upon the opening of 356 international road transport routes from 73 road ports. Port and shipping services have been deeply furthered, with Pakistan Gwadar Port transferred to China for operation, Greece Piraeus Port finished Phase-1 51\% stock exchange, and Sri Lanka Colombo port city, Sri Lanka Hambantota Port Phase-2 project, Israel Ashdod Port, and Abu Dhabi Port Khalifa container terminal projects running smoothly, while Algeria Algiers new airport has made solid progress.

By the end of 2016, Chinese government had signed air transport agreements with the governments of $62 \mathrm{~B} \& \mathrm{R}$ countries, and opened direct flight routes with 43 countries on over 4,200 flights. Air China, China Southern Airlines, China Eastern Airlines, and Hainan Airlines have founded overseas business departments for international air transport service, delivering the Air Silk Road rapidly-increasing accessibility and convenience. Besides, actively promoting bi- and multi-lateral cooperation mechanism and policy standard matching, China has signed over 130 bi- and multi-lateral agreements in railway, road, waterway, aviation, and postage with $\mathrm{B} \& \mathrm{R}$ countries, which included 16 bi- and multi-lateral transport facilitation agreements with over $15 \mathrm{~B} \& \mathrm{R}$ countries, 38 bi- and multi-lateral regional maritime transport agreements with $47 \mathrm{~B} \& \mathrm{R}$ countries, and a MOU with EU Commission commencing China-Europe connectivity platform cooperation. By the end of 2017, 3673 regular trains named "Sino-Europe Train" were transported from 38 China's cities to 36 European cities, and the transit time shorten to 12-14 days from about 30-40 days at beginning.

\subsection{Energy and Telecommunication Facility and Technology Cooperation Has Working Out Solid Progress}

China-Myanmar oil and gas pipeline has been formally delivered to operation; Middle Asia natural gas pipeline Line D, China-Russia natural gas pipeline East Line, China-North-Korea Tumen-Ra Son electric Transmission line have commenced construction; Laos $230 \mathrm{KV}$ northern power grid, Ethiopia GDHA500 kilovolt transmission project, Pakistan Neelum Jay Lum hydropower station will put into production in commissioning; Laos Nam Tha 1 hydropower station, Pakistan Karot hydropower station are implementing smoothly; China realized grid connectivity with Russia, Mongolia, Kyrgyzstan, Vietnam, Laos, and Myanmar; regional power cooperation in China-Pakistan Economic Corridor, Great Mekong Subregion have acquired concrete progress, whose mechanism has been improving. SMW5 submarine optical cable, Tanzania National ICT broadband backbone network have delivered to operation; China-Myanmar, China-Pakistan, China-Kyrgyzstan, China-Russia cross-border optical cable information passageways and other symbolic projects have reached significant progress; Asia-Pacific international submarine cable and Zhongxing-18 satellite and other information passageway projects is speeding up construction, and Bangladesh national data center project is making great progress; in telecommunication category, China is implementing connection and mutual recognition procedures in categories including standard system, inspection and quarantine, certification and accreditation, standards and measurements, and statistics, rendering the level of connectivity continuously lifting.

\section{Infrastructure Construction Has Entered the Stage of International Connectivity and Intelligent Development}

Started in the age of natural economy, the ancient Silk Road was established on the modes of caravan of camels and horses, and sailing boats. It was first for the transportation and trade of cargo, and gradually promote the communication and integration of different regions and peoples and collisions and distillation of various cultures. Since the 1800s, modern infrastructure has been upgrading with human civilization and technology development, and unprecedentedly transformed the geographical connection and time-space conception on the earth, whose meanings have been richer and fundamentally influenced the track and direction of global economic, social, political, cultural, and military development $[2,4]$.

\subsection{The Requirement for Infrastructure Construction Is Huge All over the World}

Infrastructure is the base of national economic and social development, which requires tremendous investment and extended industry chain, and has active effects on boosting economy and improve competitiveness. Nowadays, seeing the lack of global economic growth and the decelerated growth of global trade, state governments and international organizations all reached the consensus on infrastructure development, and regard the new round of infrastructure construction as the important drive for economy boost. Many developed countries have developed a relatively complete infrastructure system in their phases of rapid growth. However, in recent decades, developed countries generally lacked the investment in infrastructure and ended up with a gradually 
obsolete infrastructure, which led to urgent demands for mega-scale upgrade $[5,9,11]$. A few developing countries has now run on the fast lane for infrastructure construction, such as China, but still are constrained by the weakness from incomplete development. Most developing countries have a weak foundation in infrastructure that has become the constraint for economic growth $[7,9,10]$. Confronted with the dual responsibilities of rapid construction and upgrading, $\mathrm{B} \& \mathrm{R}$ involves many countries with large quantity, wide-ranging scope and huge development gap, most of which have backward infrastructure and limited connectivity, for example countries in Central Asia, are eager to boost economy and improve public benefit from accelerated infrastructure development, thus to generate tremendous construction demands [8].

\subsection{The Infrastructure and Facilitate Need to Be Upgraded in the future}

Under the context of globalization, international cross-region infrastructure connectivity has become a more and more obvious trend. Technology development and informatization facilitate the upgrading in transportation, energy and telecommunication, and push the hard and soft infrastructure to a more advanced, more convenient, and more intelligent direction at the same time. Modern transportation technology is developing rapidly at marine-land-aero three-dimensional track at a faster and faster speed, larger and larger capacity, and higher and higher level of intelligence. Modern energy production and transmission technology enables power global and regional grid distribution, together with the breakthrough clean energy, green energy, intelligent grid, become the catalyst for the new round of energy production and consumption revolution [6]. Modern telecommunication technology has led human being into the era of complete informatization, the rapid development of new communication technology, big data, cloud computing, and Internet of Things has crept over every single corner of the world. Network connectivity and intelligentization are leading the new round of global infrastructure construction.

After decades of development, China has developed competitive technological advantages and comprehensive industry system in infrastructure planning, construction, surveying and design, engineering construction, equipment construction, operation and management. To promote B\&R Initiative, we need to follow the trend of global infrastructure network, deliver diverse policies on the basis of market characteristics of different countries or regions, render breakthroughs in national key projects, and facilitate infrastructure industry going-out and international capacity cooperation [11].

\section{Build the Bridge of Worldwide Common Prosperity on Infrastructure Connectivity}

History proves that only could we eliminate the poverty gap and the cultural confliction, which root in the isolation and closeness, will we be able to bring the harmonious order and common prosperity to the world. Even though we had the ways like the ancient Silk Road to promote trade exchange and culture convergence in history, what lies behind is the hardship and expenses from thousands of years' blood and tears, not to say the inherent consciousness of hegemony-seekers and colonists to conquer and dominate the world by military hardware and merciless weapons. Since modern times, Mackinder and Mahan reviewed the world landscape from the perspective of a conqueror and proposed to conquer the world and carve up the resources and market. Under the context of global economic integration and multi-polarization, B\&R Initiative brings a new thinking from peace, win-win, responsibility, and inclusiveness [3, 4].

First, to insist the conception of opening-up and inclusiveness. B\&R builds an equal and voluntary cooperation platform for the countries and regions with different levels of development and different social systems from different parts of the world. It is a rather inclusive than exclusive relationship with the development initiatives and other existed bi- and multi-lateral economic and trade cooperation mechanism.

Second, to promote the establishment of transnational capacity cooperation and global integrated market. With the essence of peaceful development, China advocates enhancing practical bi- or multi-lateral industrial cooperation, mega infrastructure construction, and the restructure of trade and logistics system, based on the comparative advantages and resource reserves, to form the new system of global economy and trade, narrow the development gap, and ultimately realize common development.

Third, to facilitate joint development, sharing and win-win. Through proposed by China, B\&R is not a solo, but an ensemble with all the $B \& R$ countries. With a comprehensive respect to the country profile characteristics, development willingness, and interest concerns, China seeks for maximized general benefits and common understanding, together promotes policy coordination, infrastructure connectivity, unimpeded trade, financial integration, and closer people-to-people ties. In this way could we boost our economy, share our development outputs, improve general welfare, and build a win-win harmonious world together.

\section{Conclusion}

The rapid development in transportation, energy and telecommunication closes the distance between people, creates new driving force to transform the world, facilitates the instant communication, and makes the world a truly global village. However, the development gap is still tremendous and many less-developed countries or regions are confronted with the dilemma of the lack of development in general and the gulf of new technology, one of whose main cause was outmoded infrastructure and deficiency in connectivity. It is the most effective measure for less-developed and developing countries to promote economy growth and improve people's life through providing modern infrastructures, as well as 
conveniently to the world. In the future, the worldwide infrastructure upgrading and connectivity will be more than a method of supporting world economically balanced development and social progress, the integrated development of transportation, energy, and telecommunication technology has been widely spread and fostered new format, and become the new engine for economy. In the construction of new-generation infrastructure network lies the rare opportunity for developing countries to realize leapfrog development. China is willing to provide experience and lessons for them to catch up the express train. Based on the principles of multilateral cooperation and joint efforts to realize infrastructure connectivity, improve the mutual connectivity, keep reaping the fruitful harvest from $B \& R$, and together build the bridge to global common prosperity.

\section{References}

[1] China's National Development and Reform Commission, Ministry of Foreign Affair, Ministry of Commerce, "Joining Heads to Build a Silk Road Economic Belt and a $21^{\text {st }}$-Century Maritime Silk Road-Vision and Actions”, Beijing, March 28, 2015.

[2] Gordon L. Clark, Maryann P. Feldman, and Meric S. Gertler, "The Oxford Handbook of Economic Geography". Oxford University Press 2003. Transl. Liu Weidong etc. The Commercial Press 2005.
[3] Wu Wenhua, Su Fengming, "China Transport 2050: Vision and Strategy". Beijing, China Communications Press Co., Ltd. 2017.

[4] H. J. Mackinder, "The Geographical Pivot of History". The Geographical Journal, published by Black Well Publishing.

[5] Carota Perez, Technological Revolutions and Financial Capital — the Dynamics of Bubbles and Golden Ages. Beijing, China People University Press, 2007.

[6] China's National Development and Reform Commission, Bureau of Energy, "Action Plan of Energy Technology Revolution (2016-2030)", Beijing, March 2016.

[7] World Economic Forum, the Global Competitiveness Report 2016-2017, 2017.

[8] Wu Wenhua, On the Predicament of the Integration of Eurasian Transportation and its Breaking-through, Speech on the International Conference of Eurasia Integration, Astana, November 11, 2012.

[9] World Bank Group, World Development Report, 1994.

[10] Asian Development Bank, Meeting Asia's Infrastructure Needs, 2017.

[11] Wu Wenhua, Sun Junling, Xiang Aibing, Study on Upgrade Strategy of Transport Infrastructure Industry in China, Beijing, China Communications Press Co., Ltd. 2018. 